\title{
HISTÓRIA DE VIDA DE PIEDADE COUTINHO COMO ÍCONE DO ES- PORTE FEMININO BRASILEIRO NO SÉCULO XX
}

\author{
Fabiano Pries Devide \\ Universidade Federal Fluminense, Niterói, Rio de Janeiro, Brasil. \\ Fabiane Rodrigues Lima Moreira \\ Universidade Federal Fluminense, Niterói, Rio de Janeiro, Brasil. \\ Felippe Saint Just Rodrigues \\ Centro Universitário Augusto Motta, Rio de Janeiro, Rio de Janeiro, Brasil. \\ Renata Silva Batista \\ Centro Universitário Augusto Motta, Rio de Janeiro, Rio de Janeiro, Brasil.
}

\begin{abstract}
Resumo
A História das Mulheres no Esporte tem se constituído como um novo campo de pesquisa, resgatando a trajetória de ex-atletas. O objetivo deste estudo foi investigar a representatividade de Piedade Coutinho na construção da História das Mulheres no esporte feminino brasileiro no séc. XX. Realizamos uma análise documental das fontes históricas no recorte temporal entre as décadas de 1930-1950, utilizando, para tal, o referencial da História das Mulheres na interface com categoria de gênero. Concluímos que Piedade Coutinho foi uma mulher pioneira na inserção das mulheres brasileiras no esporte de competição, sendo destaque nos Jogos Olímpicos de 1936, 1948 e 1952, contribuindo para transformar representações de gênero associadas às mulheres na sociedade brasileira.

Palavras-chave: História das Mulheres. Esporte. Natação. Gênero.
\end{abstract}

\section{Introdução}

A História tem investigado um sujeito universal, o "Homem", pressupondo a existência das mulheres, desconsiderando distinções decorrentes da ordem de gênero. Intelectuais da área têm buscado construir uma História das Mulheres, considerando sua importância para a o contexto social em diferentes culturas, posicionando-as como agentes de sua própria trajetória (SCOTT, 2011; SOIHET, 2011). A História das Mulheres conquistou espaço na pesquisa científica ao demonstrar sua identidade frente à História oficial (SCOTT, 2011). Para tal, foi necessário perceber que mulheres possuem características próprias, com papéis distintos e interferem na sociedade, construindo cultura, demarcando diferenças históricas, culturais e sociais entre os universos masculino e feminino.

Quanto à História das Mulheres no Esporte, área com avanços significativos na produção acadêmica da Educação Física (GOELLNER, 1998; 2003; MOURÃO, 2000; DEVIDE, 2003, 2005a, 2012, 2017); intelectuais como Scott (1995), Pfister (1997) e Goellner (2007) sugerem desde a virada do século, que o "gênero" seja adotado como categoria analítica, a fim de refletir sobre a inserção das mulheres nos esportes. 


\section{Metodologia}

Os dados reunidos neste estudo compreendem o recorte histórico entre as décadas de 1930 e 1950, quando Piedade Coutinho surgiu no esporte, destacando-se em competições, despontando precocemente no cenário internacional da natação feminina, com destaque para sua participação nos Jogos Olímpicos de Berlim, em 1936, aos 16 anos.

Nesse sentido, procedemos à ordenação das fontes primárias, representadas pelos jornais, revistas, relatórios e imagens sobre a trajetória de Piedade Coutinho. Tais fontes foram reunidas a partir de visitas sistemáticas aos acervos do Arquivo Nacional, do Jornal dos Sports, da Fundação Biblioteca Nacional, da Biblioteca do Comitê Olímpico Brasileiro, Museu Hans Nobling (Esporte Clube Pinheiros), além dos clubes que Piedade Coutinho representou como atleta, a saber: o Fluminense Football Club (FFC), o Clube de Regatas Guanabara (CRG), o Clube de Regatas Flamengo (CRF) e Botafogo Futebol e Regatas (BFR), instituições localizadas no Rio de Janeiro.

Para a interpretação dessas fontes, nos remetemos às reflexões dos referenciais teóricos e metodológicos da História das Mulheres, ${ }^{1}$ dos Estudos de Gênero ${ }^{2}$ com foco no Esporte e da Análise do Discurso (PÊCHEUX, 2016; BRANDÃO, 2018). Tais referenciais nos auxiliaram na aproximação dos textos representados pelas fontes, através das quais construímos as interpretações sobre a participação de Piedade Coutinho como uma mulher pioneira e uma referência na História das Mulheres no Esporte no Brasil.

Neste percurso, reconhecemos que a história de leitura e a memória discursiva do pesquisador influenciam sua abordagem às fontes primárias, ao abarcar o seu objeto de estudo com sua subjetividade, no intuito de, a partir de um volume e diversidade expressiva de fontes, produzir uma descrição aprofundada e contextualizada do seu objeto de pesquisa (BURKE, 2011; SHARPE, 2011).

\section{$O$ cenário da Natação Feminina no Brasil na primeira metade do séc. XX}

No início do século XX no Brasil, a natação era interpretada como uma das modalidades ideais às mulheres, reflexo das representações de intelectuais e da influência cultural europeia nas cidades do Rio de Janeiro e São Paulo (SCHPUN, 1999). A crença de que a natação não comprometeria a feminilidade, não necessitava força física e não prejudicava as virtudes femininas, tornava-a uma ferramenta importante para a eugenia - um dos interesses do Estado, contribuindo para a formação de mulheres saudáveis, aptas a gerar filhos fortes, atendendo às expectativas acerca dos papéis de gênero atribuídos às mulheres à época (GOELLNER, 2003; DEVIDE, 2012).

Como esporte responsável pela inserção das mulheres sul-americanas nos Jogos Olímpicos Modernos, a natação se constituiu no cenário ideal para conquistas femininas no esporte e para a emancipação de mulheres ativas, que paulatinamente romperam os limites da esfera privada, dos cuidados com o lar e com a família (GOELLNER, 1998; MOURÃO, 2000) para conquistarem a esfera pública dos eventos esportivos, cuja audiência masculina e a cobertura da mídia eram um sucesso (DEVIDE, 2004; DEVIDE; VOTRE, 2012).

\footnotetext{
${ }^{1}$ A História das Mulheres busca incluí-las como sujeitos da sua própria história. Oferece uma nova leitura sobre verdades históricas estabelecidas, legitimando-se pelo reconhecimento da experiência singular das mulheres, criando uma identidade coletiva e assinalando sua diferença (SCOTT, 2011; SOIHET, 2011).

${ }^{2}$ Os Estudos de Gênero se consolidam como uma área de pesquisa na Educação Física no Brasil no século XXI, com ampla produção científica, linhas de pesquisa em programas de pós-graduação stricto sensu, grupos de pesquisa cadastrados no CNPq, grupos de trabalho atuantes em entidades científicas, como o Colégio Brasileiro de Ciências do Esporte, além do aumento da produção acadêmica nos diferentes formatos (DEVIDE et at., 2011; WENETZ; SWENGBER; DORNELLES, 2017).
} 
Muitas atletas se destacaram e contribuíram para o desenvolvimento da natação na primeira metade do século XX no Brasil, recorte histórico desta pesquisa. Destacamos: Piedade Coutinho, Maria Lenk, Edith Groba, Eleonora Schmitt, Scyla Venâncio, Sieglinde Lenk e Helena Salles, presentes em edições dos Jogos Olímpicos de Los Angeles, 1932; Berlim, 1936; Londres, 1948; e Helsinque, 1952, quando o esporte feminino no Brasil, especificamente a natação, apresentou grande desenvolvimento (DEVIDE, 2003; 2005b, 2005c; 2012).

Foto 1 - Piedade Coutinho, aos 16 anos, no início da carreira

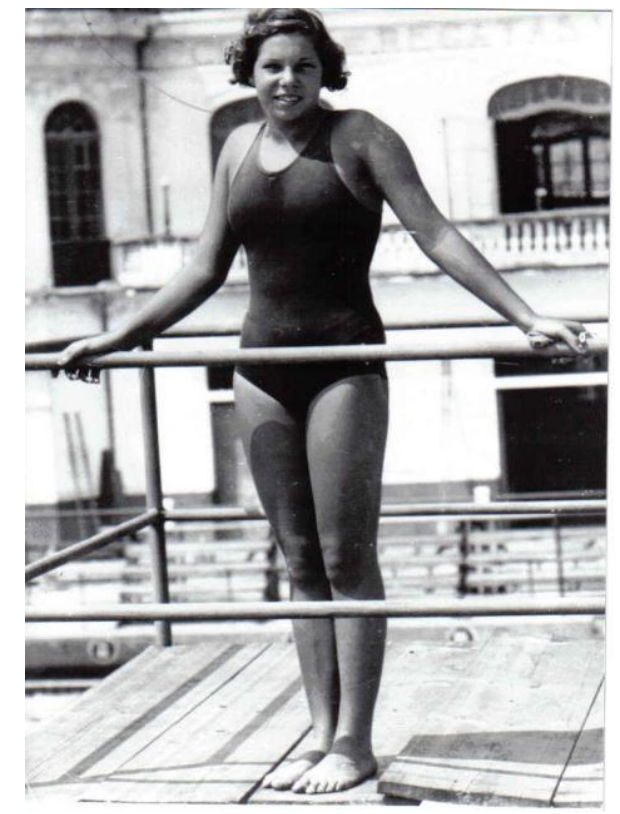

Fonte: Arquivo Nacional/RJ, 1936.

\section{Piedade Coutinho: a "menina prodígio"}

Em meio ao cenário em que a natação se destacava por corroborar com os propósitos higiênicos e eugênicos do Estado, o ano de 1935 foi marcado pela construção de piscinas e o aumento do número de competições, revelando novos nomes no esporte. Surge, então, com 15 anos, Piedade Coutinho Azevedo, que em março deste ano despontou no Campeonato Brasileiro, primeiro a incluir provas femininas, realizado no CRG, no Rio de Janeiro (DEVIDE, 2012).

No mesmo ano iniciaram-se as eliminatórias para seleção brasileira de natação que representaria o país nos XI Jogos Olímpicos de Berlim. A Confederação Brasileira de Desportos (CBD) realizou no Rio de Janeiro o III Campeonato Sul-Americano de Natação e o I Campeonato Feminino. A Revista de Educação Física destacou o excelente desempenho das nadadoras que trouxeram o título feminino:

Se no campeonato dos homens, não tivemos a colocação desejada, no certamen sulamericano feminino, o valoroso grupo de brasileiras que foram às raias, conseguiu para o Brasil o honroso titulo de campeão. (...) O valor do feito das nossas patricias, é, pois, merecedor das homenagens de todos os brasileiros. (Rio de Janeiro, ano 4, n. 22, p. 14, maio 1935$)^{3}$

\footnotetext{
${ }^{3}$ Para fins deste artigo, as transcrições de fontes primárias, representadas por excertos de reportagens ou títulos de publicações periódicas do período histórico pesquisado - décadas de 1930-1950 - tiveram a sua redação original mantida, com o português utilizado na primeira metade do século XX, assim como as suas modificações, 
O Campeonato Sul-Americano deu início à carreira internacional de Piedade Coutinho. Além dela, Maria Lenk, Sieglinde Lenk, Hilda Dias, Helena Salles e Nylsa Lemos também participaram (PARRA, s.d.). Na época, em resposta à falta de atenção dispensada pela CBD aos esportes aquáticos, surgiu a Federação Brasileira de Natação (FBN), a qual se filiaram as demais, "Especializadas": Liga Carioca de Natação (LCN), Liga de Esportes da Marinha (LEM) e a Federação Paulista de Natação (FPN), promovendo uma separação política dos atletas filiados a uma ou a outra. ${ }^{4}$

Entre 1935 e 1936, ocorreram competições de "Preparação Olímpica", acompanhadas pela imprensa esportiva. Como os(as) atletas representantes da CBD não podiam participar, Piedade Coutinho, com boas marcas no nado livre, não aparecia no cenário nacional ou tinha seus recordes homologados, competindo somente no Campeonato Brasileiro. Entretanto, em maio de 1936, na piscina do Clube de Regatas Tietê (CRT), sob a organização da FBN, Piedade venceu os 400 metros livre com a marca de 5'43" $4 / 10$, quebrando o recorde brasileiro ${ }^{5}$ (DEVIDE, 2012).

Com popularidade no Rio de Janeiro, Piedade destacava-se na natação nacional com resultados surpreendentes ${ }^{6}$ para a idade e tempo de treino. Graças aos resultados, ela garantiu lugar na equipe da CBD, mesmo não participando das "Preparações Olímpicas" organizadas pela LEM. A imprensa destacou no seu embarque para Berlim: "Piedade, A 'Mascote' Dos Brasileiros - Um episódio que demonstra a popularidade de "filhinha"':

O embarque da delegação brasileira hontem, pelo "Alcantara" veio demonstrar a grande popularidade de Piedade Coutinho, a "Menina Prodígio". A "nageuse" guanabarina tinha sempre em volta de si [...] admiradores. [...] Piedade Coutinho, que se fazia acompanhar de seus progenitores [...]. Abordada pela reportagem de "Jornal dos Sports", Piedade disse-nos: "-Sinto-me no dia mais feliz da minha vida. O meu maior desejo era correr nas Olympiadas de Berlim. Estou com um preparo technico aprimorado, e, estou certa, saberei cumprir com o meu dever, fazendo tudo pelo bom nome do Brasil". (Jornal dos Sports, Rio de Janeiro, ano VI, n. 2053, p. 1-4, 8 jul. 1936, grifos nossos)

como pode ser inferido pela mudança na grafia do nome de um mesmo periódico no período pesquisado, como a Revista Sport Illustrado, que a partir de 1942, mudou sua grafia para Esporte Illustrado.

${ }^{4} \mathrm{O}$ impasse político advindo do surgimento dessa Instituição durou até os Jogos de Berlim, quando se apresentaram duas delegações do Brasil, uma com o reconhecimento do Comitê Olímpico Internacional (COI) e outra da CBD (CARDOSO, 2000; PAIOLI, s.d), impactando o desempenho de atletas como Piedade Coutinho, que quase ficou ausente dos Jogos Olímpicos de Berlim por ser filiada à CBD.

${ }^{5}$ A Gazeta, São Paulo, anno V, n. 531, 10 maio 1936.

${ }^{6}$ Desde então, Piedade estabeleceu 28 recordes em sua carreira atlética (PARRA, s.d.). 
Foto 2 - Piedade Coutinho a bordo do navio Alcântara, a caminho dos Jogos Olímpicos de Berlim, em companhia de sua mãe, ao lado dos presidentes do CRG e da Federação Aquática do Rio de Janeiro

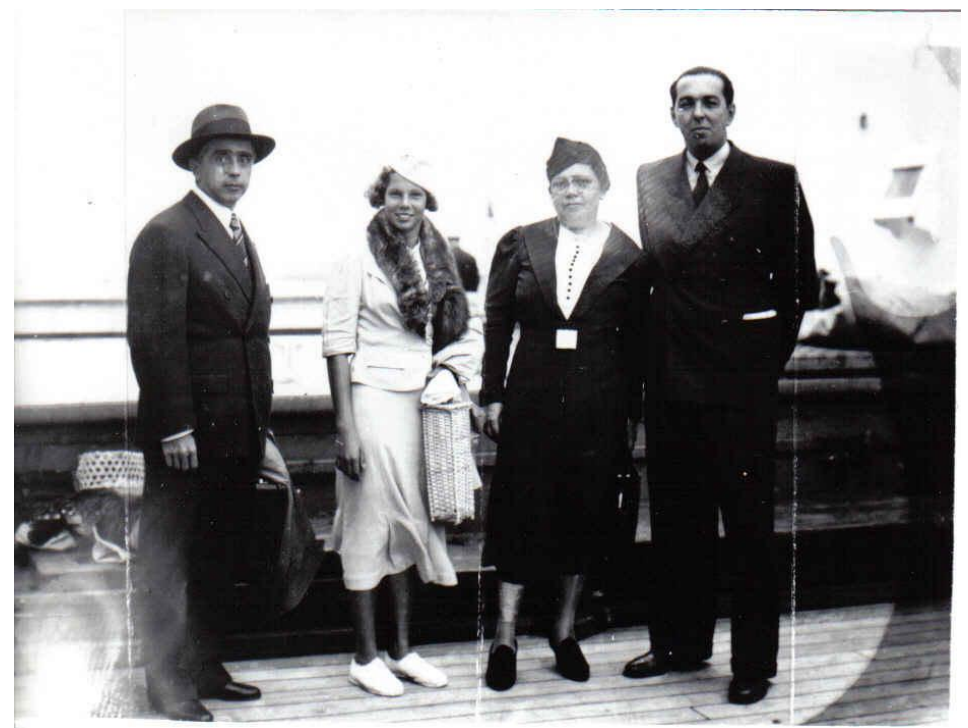

Fonte: Arquivo Nacional/RJ, 1936.

As duas delegações que representariam o Brasil nos Jogos Olímpicos de Berlim viajaram separadas: a do COB embarcou no navio "General Artigas", saindo de Santos e passando pelo Rio de Janeiro; enquanto a da CBD partiu no navio "Alcântara", com saída do Rio de Janeiro, acompanhada pelo Jornal dos Sports:

Piedade Coutinho, a maior esperança da natação brasileira foi a ultima a receber o passaporte. O Sr. Luiz Aranha, ao fazer-lhe a entrega [...], disse-lha: “-Você é a maior esperança da delegação e a única moça que representará o Brasil nas Olympiadas de Berlim. Você servirá de 'mascote' à nossa representação, que embarca cheia de fé e esperança em representar o Brasil condignamente". Filhinha [seu apelido] recebeu o passaporte sob aclamações [...]. (Jornal dos Sports, Rio de Janeiro, ano VI, n. 2052, p. 6, 7 jul. 1936, grifo nosso)

Faz-se relevante interpretar o significado associado à Piedade Coutinho, ao atribuir-lhe termos como "mascote", "menina", "garota", o apelido de "Filinha", assim como o destaque de seu embarque sob a presença dos "progenitores". A linguagem proferida pela mídia da época associava à atleta a representação de fragilidade, por sua mocidade e inexperiência, tratando-a como uma exceção - única mulher na delegação enviada pela CBD - e pelo uso do diminuitivo para lhe apelidar, reforçando a necessidade de cuidados associada às mulheres no início do século XX (GOELLNER, 1998, 2003; MOURÃO, 2000; LOURO, 2017).

Ao desembarcar na Alemanha, a delegação da CBD não teve permissão para se instalar na vila olímpica, fato que ganhou notícia na imprensa e só se resolveu momentos antes da abertura dos Jogos, com a união das duas delegações. Passado o episódio, iniciaram-se as participações das nadadoras nas piscinas, dentre as quais Piedade Coutinho, que surpreendeu na primeira prova, os 100 metros livre, alcançando a semifinal e colocando-se em $8^{\circ}$ lugar (ORGANISATIONSKOMITEE FÜR DIE XI OLYMPIADE, 1936, p. 968). Piedade Coutinho, a "Garota Prodígio", 7 apelido adotado pela imprensa, passou a ser a maior esperança do Brasil em Berlim, desconstruindo o estereótipo de gênero que associava as mulheres à fragilidade, destacando-se no âmbito da delegação brasileira no contexto dos Jogos Olímpicos.

\footnotetext{
7 Jornal dos Sports, Rio de Janeiro, ano VI, n. 2081, p. 2, 9 ago.1936.
} 
Surpresa tiveram os espectadores, quando ao disputar a prova dos 400 metros livre, Piedade classificou-se para a semifinal com o terceiro melhor tempo. O Jornal dos Sports publicou em reportagem de capa a foto de Piedade, com a manchete "Piedade Coutinho Em $3^{\circ}$ Logar Nos 400 Metros", seguida do texto; "Piedade Coutinho, a maior esperança da natação feminina brasileira, conseguiu hontem, um optimo $3^{\circ}$ logar nas eliminatórias de 400 metros nado livre". ${ }^{8}$ No dia seguinte, classificou-se para a final, alimentando expectativas de uma medalha olímpica:

Piedade Coutinho Finalista!: a prodigiosa nadadora nacional conseguiu o $4^{\circ}$ resultado do dia [...]. De tantos nadadores e nadadoras que o Brasil enviou a Berlim, representando a sua melhor classe aquática, a representante mais menina, a "mascote" [...], foi a unica que logrou galgar o "olympo" dos privillegiados. [...] Todo o Brasil ficará hoje attento aos apparelhos retransmissores de radio, aos jornaes que vão divulgar o desfecho da final dos 400 metros para moças. Piedade Coutinho é a preocupação de hoje em todo o Brasil. (Jornal dos Sports, Rio de Janeiro, ano VI, n. 2086, p. 1-6, 15 ago. 1936, grifo nosso)

No dia seguinte, o Jornal dos Sports noticiou: "Piedade Coutinho $5^{\circ}$ Logar nos 400 metros! O esforço brilhante da nossa melhor nadadora". ${ }^{9}$ O resultado de Piedade é a melhor classificação de uma nadadora brasileira, até hoje, nas provas em piscina, nos Jogos Olímpicos Modernos, tendo sido igualada somente ao desempenho da nadadora Joana Maranhão, nos Jogos Olímpicos de Atenas, 2004. ${ }^{10}$

Apesar dos resultados obtidos em Berlim, o final da década de 1930 não trouxe grandes feitos a Piedade Coutinho, que se sagrou campeã nos 400 metros nado livre no SulAmericano de Montevidéu, em 1937. Sob o discurso de diminuir os custos, a CBD não a levou ao Sul-Americano de Guayaquil, em 1939. Com o advento da II Guerra Mundial, os Jogos Olímpicos de Tóquio, em 1940 e os Jogos Olímpicos de 1944, foram suspensos.

Nesse intervalo, em 1940, representando o CRF, Piedade Coutinho, desafiando os limites de idade e da sociedade da época, se dispõe a tentar quebrar seu recorde brasileiro dos 1.500 metros nado livre. Para surpresa de todos e dela própria, a atleta quebrou, além do recorde dos 1.500 metros, três recordes sul-americanos, ficando a 26 segundos do recorde mundial da prova. O feito lhe rendeu a manchete "Devastação de Records: Reportagem sensacional sobre a maior façanha de Piedade Coutinho". 11

No ano seguinte, no Campeonato Brasileiro realizado em São Paulo, Piedade Coutinho se destacou ao marcar 45,5 pontos, fundamentais para a vitória da LCN. O tempo de Piedade nos 100 metros livre figurou entre os melhores do mundo.

Piedade Coutinho foi, sem duvida, a estrella de primeira grandeza das primeiras provas do certamen. [...] A grande campeã do Flamengo marcou 1.08.5, ${ }^{12}$ tempo que raríssimas nadadoras do mundo conseguem attingir. [...] á extraordinária recordista carioca, brasileira e sul-americana, todas as honras do Pacaembu [...]. (Sport Illustrado, Rio de Janeiro, ano 3, n. 145, p. 3-8, 16 jan. 1941)

\footnotetext{
${ }^{8}$ Jornal dos Sports, Rio de Janeiro, ano VI, n. 2085, p. 1-4, 14 ago. 1936.

${ }^{9}$ Jornal dos Sports, Rio de Janeiro, ano VI, n. 2087, p. 1-6, 16 ago. 1936.

${ }^{10}$ Nos Jogos Olímpicos do Rio de Janeiro, em 2016, Poliana Okimoto conquistou a medalha de bronze na prova de maratona aquática, na distância de $10 \mathrm{~km}$. Entretanto, nas provas em piscina, o quinto lugar de Piedade Coutinho, em 1936; e de Joana Maranhão, em 2004; ainda são os melhores desempenhos de mulheres no evento.

${ }^{11}$ Piedade marcou 7'08" $8 / 10$ na passagem dos 500 metros; 11'39" nos 800 metros (recorde anterior: 12 '57"); 14'40'2 nos 1000 metros nado livre (recorde anterior: 16'15”2); 22'11"8 nos 1500 metros (recorde anterior: 25'27'6) (Sport Illustrado, Rio de Janeiro, ano 3, n. 139, p. 9, 5 dez. 1940).

${ }^{12}$ Com este tempo feito em 1941, Piedade Coutinho seria finalista nos 100 metros nado livre nos Jogos Olímpicos de Londres, realizados sete anos depois, quando aos 28 anos, classificou-se em $11^{\circ}$ lugar (ORGANISING COMMITTEE FOR THE XIV OLYMPIAD, 1948, p. 466).
} 
No mesmo ano, parte com destino a Viña del Mar, no Chile, para disputar o VII SulAmericano, os "Astros e estrellas selecionados pela CBD dentre os quais constava, um authentico 'four' de campeonissimas, Piedade Coutinho, Maria e Sieglinde Lenk, Cecília Heilborn". ${ }^{13}$ Dentre os excelentes resultados das nadadoras brasileiras, Piedade Coutinho marcou 50,5 dos 174 pontos da equipe feminina, o que lhe rendeu o título de melhor atleta do evento. "Novo e brilhante feito de Piedade: a nadadora Patricia quebrou a marca que Jeannete Campbell tinha há três annos - 2'33" 8". ${ }^{14}$ A Revista Sport Illustrado escreveu: "Piedade Coutinho foi, sem favor, a maior figura do VII Sul-Americano. Dos 4 records registrados, tres lhe pertencem, sendo que ficou detentora dos unicos dois records individuaes". ${ }^{15} \mathrm{O}$ resultado da delegação rendeu a posse da Taça América, dada à equipe que mais primeiros lugares conquistasse no evento.

Ao retornarem ao Brasil, a delegação foi recebida com méritos, mas apesar das nadadoras serem responsáveis pelo triunfo do Brasil e ganharem algumas fotos na imprensa, a invisibilidade feminina permanecia nas manchetes: "Apotheotica recepção aos triumphadores de Viña del Mar [...] os herois de Viña del Mar [...] Elles se julgaram apenas parcella de uma gloria". ${ }^{16}$ O Jornal dos Sports publicou na capa uma fotografia da equipe feminina de natação, com a manchete: "Terão uma recepção apotheotica os campeões Sul-americanos - A CBD estuda a organização de um grande programma de homenagens - possível uma exhibição dos nadadores em Porto Alegre". ${ }^{17}$ Em março de 1941, o mesmo periódico publicou uma foto de Piedade e das irmãs Lenk na capa, com a manchete: "Glória aos campeões! A recepção aos vencedores do Sul-Americano de Natação". ${ }^{18}$ Por fim, ainda sobre este evento, especificamente o desembarque da equipe nacional na Praça Mauá, a Sport Illustrado publicou:

Os heroes de Viña Del Mar [...] em pleno Caes Mauá tivemos o ensejo de falar com todos os nadadores. [...] Elles se julgaram apenas parcellas de uma gloria [...]. Na sede do C.R. Botafogo, [...] os campeões sul-americanos foram recebidos [...] caberá num futuro bem proximo repetir a proeza dos athletas e dos nadadores heróes [...]" (Sport Illustrado, Rio de Janeiro, ano 3, n. 153, p. 3, 15-18, 13 mar. 1941, grifo nosso).

A invisibilidade do gênero feminino na redação do texto demonstra que, na ausência das fotos, o leitor poderia pressupor que a equipe nacional provavelmente teria ido ao Chile sem mulheres atletas. A tendência de se referenciar as atletas com o gênero masculino pela imprensa esportiva sinalizava sua invisibilidade no esporte, apesar dos resultados internacionais expressivos do momento, ilustrando como o uso da linguagem se constitui num dispositivo que colabora(va) para delimitar espaços de gênero, inviabilizando as mulheres na sociedade e no esporte de competição, uma área de reserva masculina na época (LOURO, 2017; DEVIDE, 2012). No que tange à natação, tal aspecto se acentuou na segunda metade do século $\mathrm{XX}$, com o advento do doping, os avanços nas pesquisas sobre Treinamento Esportivo e a cultura paternalista em relação ao corpo feminino, que ao se envolver com a prática competitiva do esporte, desenvolvia musculatura e modificava suas formas, contestando a feminilidade hegemônica imposta à época (DEVIDE, 2003, 2012; DEVIDE; VOTRE, 2005).

Após o Sul-Americano de Viña del Mar, Piedade Coutinho e outras nadadoras afastaram-se das piscinas. O periódico Esporte Ilustrado escreveu: "Piedade Coutinho; a grande

\footnotetext{
${ }^{13}$ Sport Illustrado, Rio de Janeiro, ano 3, n. 147, não paginado, 30 jan. 1941.

${ }^{14}$ Jornal dos Sports, Rio de Janeiro, n. 3530, p. 1-4, 12 fev. 1941.

${ }^{15}$ Sport Illustrado, Rio de Janeiro, ano 3, n. 150, p. 16, 20 fev. 1941.

${ }^{16}$ Sport Illustrado, Rio de Janeiro, ano 3, n. 153, p. 3, 15-18, 13 mar. 1941, grifo nosso.

${ }_{17}^{17}$ Jornal dos Sports, Rio de Janeiro, n. 3537, p. 1, 19 fev. 1941, grifo nosso.

${ }^{18}$ Jornal dos Sports, Rio de Janeiro, n. 3543, p. 1, 1 mar. 1941, grifo nosso.
} 
campeã sul-americana. O seu afastamento das nossas piscinas marcou a fase decrescente que ora preocupa os dirigentes de nossa natação". ${ }^{19}$ Aliado à falta do surgimento de novos nomes, o fato desencadeou um declínio nos resultados da natação nacional, já que a equipe feminina era responsável pelos triunfos da modalidade. Maurício Becken escreveu sobre a representação brasileira na natação carioca e paulista a nível internacional:

No setor feminino, Maria Lenk, em São Paulo e Piedade Coutinho, no Rio, começaram a brilhar. E junto com elas outras "nageuses" [...]. Houve época em que a C.B.D. [...] não ligou á natação. [...] depois tivemos aquela jornada magnífica de Viña Del Mar onde [...] acreditavamos [...] que daí para diante somente sucessos deveriam marcar nossa aquática. Mas nossos nadadores recuaram. $\mathrm{O}$ afastamento de lides de renomados campeões e o não aparecimento de outros [...], permitiu um declinio. ${ }^{20}$

No contexto social em que as atletas se afastavam do esporte para atenderem às expectativas sociais acerca dos papéis de gênero (GOELLNER, 1998, 2003; MOURÃO, 2000), Piedade Coutinho tornou-se pioneira ao retornar aos treinos e competições em 1943, casada e mãe de Frederico, que a acompanhava nas competições onde ela tornou a quebrar os seus próprios recordes.

Então, em 1946, às vésperas do Campeonato Sul-Americano, a convite dos técnicos, Piedade reforçou a seleção. Nos meses anteriores à competição no Rio de Janeiro, a imprensa focalizou atletas que retornavam às piscinas, como ela: "Piedade Coutinho está em fórma. Venceu bem as suas provas no campeonato e está apta a brilhar no sul-americano". ${ }^{21}$ A nadadora confirmou as expectativas da imprensa ao destacar-se como responsável pela vitória do revezamento feminino: "E o público vibrou intensamente vendo a nossa campeã, ao mesmo tempo que se desforrava da única derrota que lhe fora imposta, assegurar ao Brasil o título feminino" (Esporte Ilustrado, Rio de Janeiro, n. 422, p. 9, 9 maio 1946).

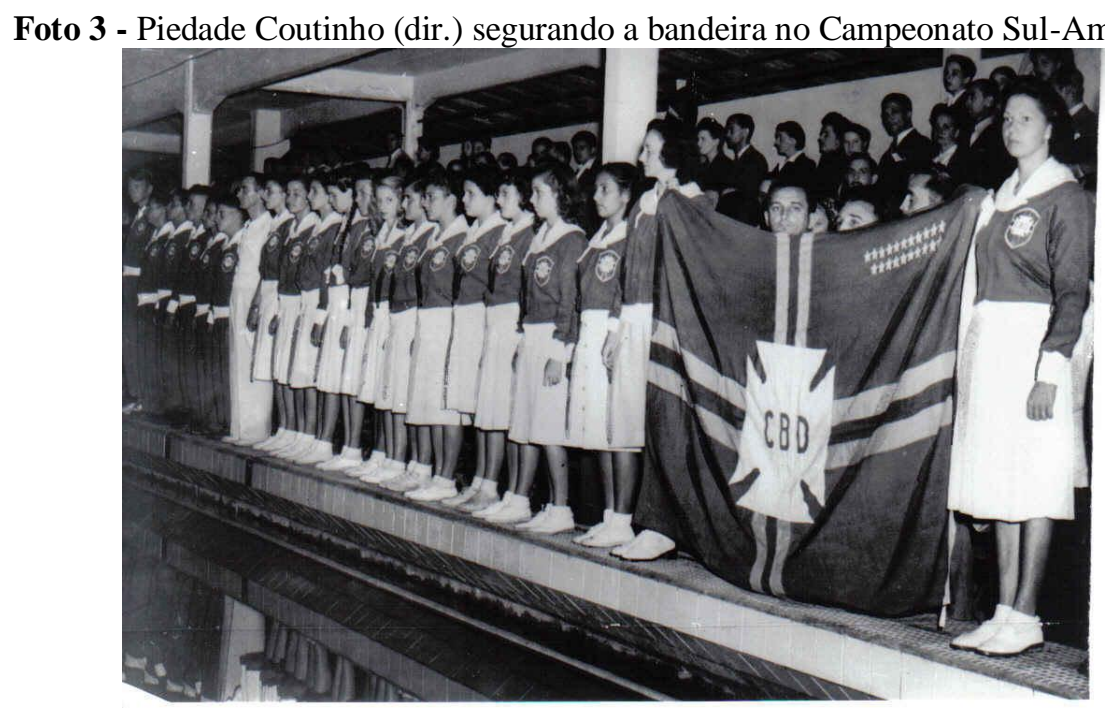

Fonte: Arquivo Nacional/RJ, 1946.

Em Buenos Aires, aos 27 anos, idade na qual atletas se aposentavam do esporte, Piedade venceu todas as provas em nado livre do Sul-Americano que marcou o seu retorno às competições internacionais. Invicta na América do Sul nas provas de nado livre, dos 100 aos

\footnotetext{
${ }^{19}$ Esporte Ilustrado, Rio de Janeiro, ano 5, n. 237, não paginado, 22 out. 1942.

${ }^{20}$ Esporte Clube Pinheiros. Álbum de recortes [doado por Willy Otto Jordan - A-828; A-832]. São Paulo: ECP.

${ }^{21}$ Esporte Ilustrado, Rio de Janeiro, n. 418, p. 4, 11 abr. 1946.
} 
1.500 metros e contrariando os princípios sociais da época: "Piedade Coutinho Tavares, é como o vinho [...] continua [...] dando combate às suas marcas antigas, ao poderio da juventude... Ontem, notável feito, [...] hoje, senhora, mãe de um filho, mas sempre firme em busca de novas glorias [...]". ${ }^{22}$ Ao analisar o discurso da imprensa, é relevante destacar dois aspectos: o primeiro, pelo fato de dez anos após sua participação em Berlim, a "menina" e "mascote" passar a ser chamada de "senhora", devido ao casamento e à maternidade; e o segundo, pelo uso do operador argumentativo "mas" para atribuir a noção de adendo, ou seja, apesar de senhora e mãe, a atleta se mantém em alta performance, assinalando como a maternidade - e implicitamente o casamento - eram interpretados como algo incompatível com a prática esportiva para as mulheres (GOELLNER, 2003; DEVIDE, 2012).

O ano de 1948 foi marcado pelo retorno dos Jogos Olímpicos após a II Guerra Mundial. Piedade Coutinho, integrando a equipe do FFC, surpreendeu, pois quando achavam que já ela havia atingido todas as metas, a atleta quebrou os recordes sul-americanos pertencentes a ela desde 1941: 'Piedade vence o tempo e o cronômetro. O 'dedo mágico' de Cachimbau fez a campeonissima derrubar todos os seus records!". ${ }^{23}$

Atual campeã Sul-Americana, Piedade alcança os índices olímpicos em uma competição preparatória para os XIV Jogos Olímpicos de Londres. Antes de partir para sua segunda participação olímpica, Piedade Coutinho, ao lado do filho Frederico, recebe da Gazeta Esportiva, o "Troféu Cásper Líbero", como a "maior atleta do Brasil" do ano.

Piedade Coutinho da Silva Tavares, [...] considerada a "maior atleta do Brasil" [...] Para se aquilatar do justo prestígio de Piedade, basta dizer que ela suplantou atletas de grande popularidade no futebol, que é o esporte mais difundido em nosso país. [...]a sua vitória teve significação muito maior, não só pelo fato de ser ela do sexo feminino, como pelo fato de se tratar de uma nadadora [...]. (Fluminense Football Club, Rio de Janeiro, ano IX, n. 104, p. 5, 1 jan. 1949)

A nadadora também recebeu da Federação Metropolitana de Natação, uma Taça de prata, em homenagem e agradecimento pelos feitos na natação nacional. ${ }^{24} \mathrm{~A}$ veterana Piedade Coutinho, com tempos melhores do que doze anos atrás, época de seu desponte no cenário nacional, fez com que Cachimbao, técnico da equipe brasileira, a visse como favorita nas provas que participaria. Em competição preparatória para os Jogos Olímpicos, Piedade marcou um dos melhores tempos do mundo nos 400 metros livre: 5'20"3/10, alcançando o índice olímpico e quebrando o recorde sul-americano na piscina do CRG. O Jornal dos Sports publicou na capa: "Piedade sensacional! Assombrosos resultados alcançados pela grande nadadora patrícia". ${ }^{25}$ Seu tempo era melhor que o da norte-americana Ann Curtis, favorita à medalha olímpica. No entanto, um impasse ainda estaria por vir: Piedade, assinalando ser uma mulher de vanguarda para a época, exigiu a presença do filho Frederico, registrada pela impressa:

Assunto ainda pendente - Piedade Coutinho Tavares e a ida às Olimpíadas: registrase, como não poderia deixar de ser, [...] intensa expectativa sobre a solução que se aguarda para que não venha faltar à delegação brasileira que irá a Londres, o concurso da nadadora Piedade Coutinho Tavares. (Jornal dos Sports, Rio de Janeiro, n. 5789, p. 1-6, 7 jul. 1948)

Importante ressaltar como, no contexto social em que às mulheres se reservavam a esfera privada do lar, a maternidade e o casamento, Piedade se manteve ativa, retornando às piscinas após casar-se e ser mãe, conciliando os papéis de esposa, mãe e atleta, desafiando os

\footnotetext{
${ }^{22}$ Esporte Ilustrado, Rio de Janeiro, n. 524, p. 3, 22 abr. 1948, grifo nosso.

${ }^{23}$ Esporte Ilustrado, Rio de Janeiro, n. 526, p. 17, 6 mai. 1948.

${ }^{24}$ Jornal dos Sports, Rio de Janeiro, n. 5779, p. 3, 25 jun. 1948

${ }^{25}$ Jornal dos Sports, Rio de Janeiro, n. 5781, p. 1-6, 27 jun. 1948.
} 
cânones de gênero da época (GOELLNER, 1998, 2003; MOURÃO, 2000; DEVIDE, 2003, 2012). De sua posição, exigiu a garantia da presença do filho para que embarcasse a Londres, conforme a imprensa noticiou: "Piedade irá: assentado definitivamente o embarque da nossa campeoníssima com a nossa delegação", explicando-se ainda:

Razões foro intime, [...] estavam a impedir sobre a ida de Piedade Coutinho Tavares a Londres. [...] dadas as magníficas 'performances', [...] seria decepcionante [...] não contarem com ela na nossa representação olímpica [...] (Jornal dos Sports, Rio de Janeiro, n. 5794, p. 1-6, 13 jul. 1948)

No fim de julho, embarcou para Londres a equipe de natação e outras modalidades, na qual Piedade Coutinho era expoente. O Jornal dos Sports fotografou e publicou o fato notório: "Piedade Coutinho [...] e o seu galante filhinho Frederico, foram sem duvida as figuras centrais. O garoto, pela sua vivacidade natural e pelo cartaz da mamãe, e Piedade por ser a mais credenciada da equipe de natação para um primeiro lugar nas provas de Londres" (Rio de Janeiro, n. 5801, p. 1-4, 21 jul. 1948, grifo nosso). A análise do discurso midiático permite identificar como a mesma utiliza marcadores para assinalar que Piedade Coutinho, apesar de ser a atleta mais "credenciada", com 28 anos, também atendia aos papéis de gênero e à exigência social da maternidade (GOELLNER, 2003).

Chegando a Londres, as atletas teriam como principal obstáculo condições adversas de alimentação e acomodações, que comprometeram seus resultados, conforme depoimentos de outras nadadoras, presentes nos Jogos Olímpicos de Londres (DEVIDE, 2012). O relatório do chefe da delegação traz alguns aspectos do cenário impróprio destinado às atletas:

Os rapazes se achavam bem instalados e satisfeitos com a alimentação, pois tinham
a assistencia do nutrólogo [...] e do cozinheiro [...]. As moças, ao contrario, queixa-
vam-se da alimentação e das acomodações que lhes haviam sido destinadas, no
sótão de um grande predio de 3 pavimentos [...] Tambem se diziam sem assistencia
num meio extranho. [...] Fiz, outrossim, ainda com autorização [...], transportar para
o referido colegio alguns generos [...] feijão, arroz, farinha e ovos, com o que melho-
rou bastante o estado de animo das moças. [...] nossas nadadoras [...] encontravam-
se a duas horas de distancia do campo de West Drayton, onde estava hospedada a
equipe masculina. [...] faziam o trajeto de Wimbledon a Wembley, tambem de oni-
bus, em pouco mais de uma hora. Viagens cansativas e sujeitas a espera do onibus
para o regresso, de pé, na praça fronteira á piscina, muitas vêses durante meia hora
ou mais. (COB, 1948, não paginado, grifo nosso)

As más condições de estadia e alimentação das nadadoras, além de demarcar uma assimetria de gênero em relação aos atletas masculinos, resultaram na piora da performance. Posteriormente, a imprensa reportou que Piedade melhorou marcas nos treinamentos. Em entrevista, o técnico da delegação comentou: "Tendo sido possível fornecer-se alimentação, Piedade acha-se agora em excelente forma, tendo se restabelecido completamente de sua indisposição anterior". ${ }^{26}$ Mas logo veio o reflexo da adversidade enfrentada. Piedade não conseguiu repetir os tempos nos 100 metros livre, restando apenas os bons resultados nos 400 metros livre e na equipe feminina de revezamento, ambas colocadas em sexto lugar. Com o filho no colo, a nadadora teve o seu desempenho analisado pela imprensa:

Dadas as condições adversas aqui imperantes, todavia, nada se poderá garantir quanto a conquista do título, mas pelo visto, seu favoritismo confirmou-se plenamente. Embora sendo o melhor das eliminatorias, o [tempo] de Piedade, ficou muito aquém dos 5'20" que ela conseguiu poucos dias antes de embarcar. (Jornal dos Sports, Rio de Janeiro, n. 5815, p. 1, 6 ago. 1948, grifo nosso)

${ }^{26}$ Jornal dos Sports, Rio de Janeiro, n. 5808, p. 4, 29 jul. 1948, grifo nosso. 
Repetindo o feito de Berlim, Piedade foi única brasileira finalista e caso tivesse repetido seu tempo das eliminatórias no Brasil, teria sido vice-campeã olímpica. ${ }^{27}$ Em 1949, Piedade venceu os 100 metros nado livre, no Campeonato Sul-Americano em Montevidéu, Uruguai, porém a argentina Eileen Holt a venceu nas demais provas de nado livre. Aos 30 anos, seguiu sua carreira e conquistou as provas de nado livre do Campeonato Brasileiro de 1950. Em 1951, na primeira edição dos Jogos Pan-Americanos, em Buenos Aires, Piedade conquistou o bronze nos 400 metros livre e no revezameto 4x100 metros livre, com Ana Santa Rita, Idamis Busin e Talita Rodrigues (UNITED STATES OLYMPIC COMMITTEE, 1999).

A veterana Piedade ainda compareceu ao Sul-Americano do Peru, 1952, sendo vicecampeã em todas as provas de nado livre, vencidas pela jovem argentina Ana Schultz (PARRA, s.d.). Os jornais enalteceram sua forma física, que permitia repetir os tempos de uma década atrás: "A nossa campeoníssima Piedade Coutinho, mesmo sem vencer, convenceu. Seu resultado foi muito bom, igualando suas marcas efetuadas há mais de dez anos". ${ }^{28}$ Com o tempo nos 400 metros livre, ${ }^{29}$ Piedade atingiu novamente o índice olímpico, para ser a primeira atleta brasileira a participar de três edições dos Jogos Olímpicos: ${ }^{30}$

Piedade, em fato inédito: Comparecerá à terceira Olimpíada. [...] Em prova final do programa de encerramento, Piedade Coutinho obtendo a segunda colocação, deixou patente a sua alta classe, superando o índice olímpico para os 400 metros livres. Outro título dos mais brilhantes na aquática mundial pois, Piedade Coutinho será a única nadadora a ter participado de três Jogos Olímpicos (Jornal dos Sports, Rio de Janeiro, n. 6924, p.1-6, 25 mar. 1952).

Os XV Jogos Olímpicos de Helsinque marcaram o final de uma geração da natação feminina, iniciada com Maria Lenk, em 1932 (DEVIDE, 2005c). Do grupo que participou em Berlim, 1936, e Londres, 1948, restaram Piedade Coutinho e Edith Groba. A primeira confirmou a boa forma, aos 32 anos, sendo semifinalista nos 400 metros livre; enquanto Edith Groba não apresentou a mesma performance que a credenciava à final olímpica (ORGANISING COMMITTEE FOR THE GAMES OF THE XV OLYMPIAD, 1952; COB, 1952).

Piedade Coutinho, a primeira atleta brasileira que participou de três edições dos Jogos Olímpicos Modernos, maior recordista sul-americana da natação à época, tornou-se diretora de natação do BFR, ${ }^{31}$ onde finalizou a carreira. Sua filha Frésia nasceu no ano seguinte aos Jogos de Helsinque. No final da década de 1950, Piedade construiu um centro de recuperação para crianças com poliomielite, chamado "Lar de Recuperação da Paralisia Infantill", ${ }^{2}$ onde através da natação, teve sucesso e reconhecimento do governo federal, sendo recebida pelo ministro da saúde, Maurício de Medeiros, quando expôs suas atividades no combate à paralisia infantil.

\footnotetext{
${ }^{27}$ Organising Committee for the XIV Olympiad (1948, p. 461).

${ }^{28}$ Jornal dos Sports, Rio de Janeiro, n. 6919, p. 6, 19 mar. 1952.

${ }^{29}$ Em julho, em competição de tentativa de recorde no FFC, Piedade fez a melhor marca da temporada nos 400 metros livres: 5'24'4, tempo que lhe renderia a final olímpica em Helsinque (Jornal dos Sports, Rio de Janeiro, n. 7011, p. 13, 6 jul. 1952).

${ }^{30}$ Relevante sublinhar que Piedade poderia alcançar a participação em cinco edições do evento, caso tivesse participado dos Jogos Olímpicos de 1940 e 1944, cancelados devido à II Guerra Mundial.

${ }^{31}$ Botafogo!, Rio de Janeiro, ano X, n. 97, p. 18, out. 1952.

${ }^{32}$ Correio da Manhã, Rio de Janeiro, 15 jun. 1958.
} 
Foto 4 - Piedade Coutinho em aula de natação no "Lar de Recuperação da Paralisia Infantil"

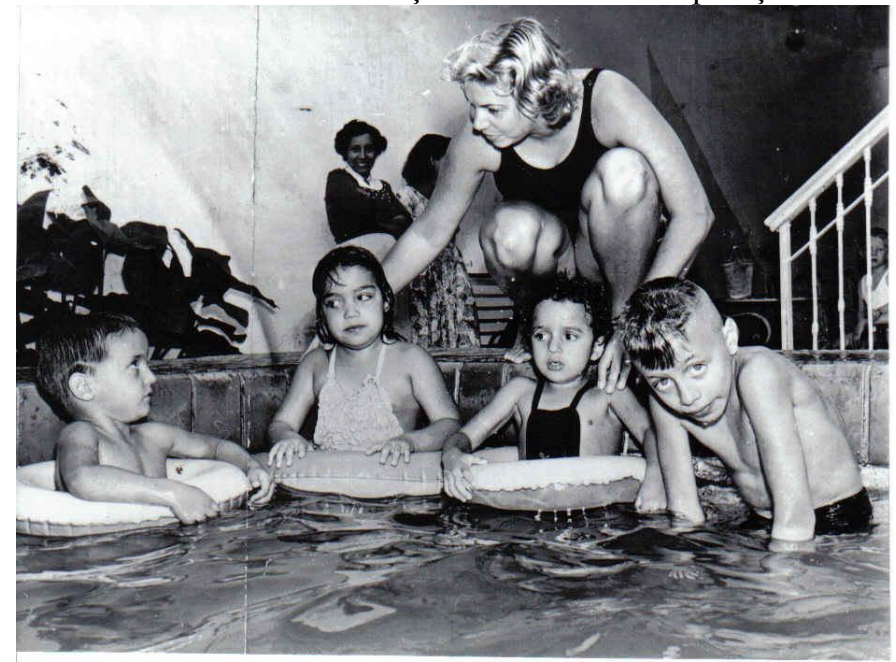

Fonte: Arquivo Nacional/RJ, [195-].

Foto 5 - Piedade Coutinho com o Ministro da Saúde, Maurício de Medeiros

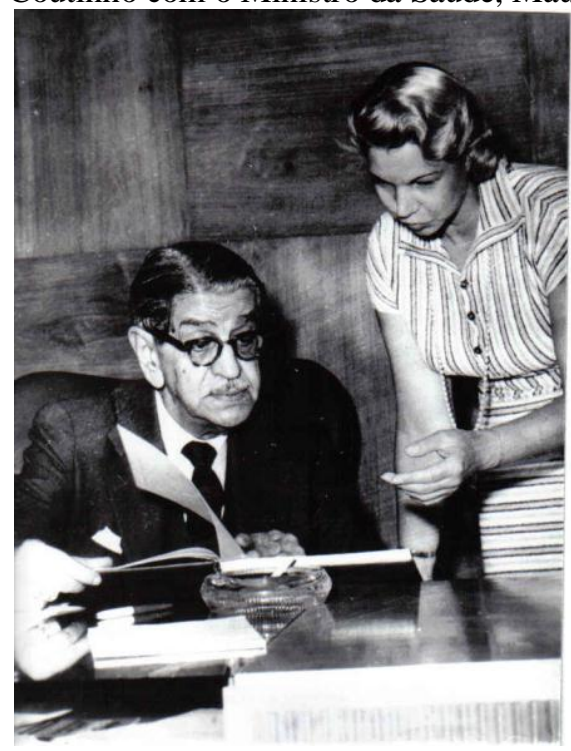

Fonte: Arquivo Nacional/RJ.

Durante a década de 1950, nas edições do Campeonato Sul-Americano, em São Paulo, 1954; Viña del Mar, 1956; e Montevidéu, 1958 (PARRA, s.d.), novas nadadoras surgiram, como Leda Carvalho, Silvia Bitran, Isa de Almeida, Idamis Busin, Lísia Barth, Gloria Funaro, entre outras (COMITÉ ORGANIZADOR DE LOS SEGUNDOS JUEGOS DEPORTIVOS PANAMERICANOS, 1955; PARRA, s.d.). Contudo, não conseguiram quebrar as marcas deixadas por Piedade Coutinho, Edith Groba e Maria Lenk nas décadas de 1940-1950.

\section{Considerações finais}

O presente estudo visa colaborar com a área da História do Esporte, com ampla produção acadêmica na Educação Física brasileira. Especificamente, teve o objetivo de resgatar a trajetória de vida esportiva de Piedade Coutinho como referência na História das Mulheres no esporte feminino brasileiro. Sendo assim, a partir do referencial teórico da História das $\mathrm{Mu}$ lheres e dos Estudos de Gênero, apresentou-se o percurso desta atleta na natação brasileira, na 
primeira metade do século XX, assim como sua contribuição no acesso das mulheres ao esporte no Brasil, sobretudo na natação.

Pautados nas fontes primárias documentais da época, representadas por jornais, revistas, relatórios e imagens, concluímos que Piedade Coutinho foi pioneira, sendo uma referência na História da Natação no país, em função de suas conquistas no esporte em nível nacional e internacional, com destaque para suas participações em três edições dos Jogos Olímpicos.

Com base em sua trajetória, podemos afirmar que a inserção e permanência de Piedade Coutinho no esporte causou impacto nas representações de gênero associadas às mulheres em nossa sociedade, ao sobrepor barreiras como a conciliação do casamento, da maternidade e do treinamento, em uma época na qual se reservava às mulheres a esfera privada, o cuidado dos filhos e a administração da casa, inaugurando, portanto, novas representações e abrindo portas para que outras mulheres se inserissem no esporte e na esfera pública.

\title{
LIFE STORY OF PIEDADE COUTINHO AS A BRAZILIAN ICON OF FEMALE SPORT IN 20TH CENTURY
}

\begin{abstract}
The History of Women in Sport has been constituted as a new field of research, rescuing the former-athletes trajectories. The objective of this study was to investigate the representative impact of Piedade Coutinho in the construction of the History of Women in the Brazilian feminine sport in XXth century. We proceeded to a documental analysis of historical sources between 1930-1950, using the theoretical framework of Women's History, and Gender as a categorical analysis. We conclude that Piedade Coutinho was a pioneer woman in the insertion of Brazilian women in competitive sport, participating of the 1936, 1948, and 1952 Olympics Games, contributing to transform representations of gender associated with women into the Brazilian society.
\end{abstract}

Keywords: Womens's History. Sport. Swimming. Gender.

\section{HISTORIA DE LA VIDA DE PIEDAD COUTINHO COMO ICONO DEL DEPORTE FEMENINO EN EL SIGLO XX}

\section{Resumen}

La historia de las mujeres en el deporte se ha constituido como un nuevo campo de investigación, rescatando a los ex atletas. El objetivo de este estudio fue investigar la representatividad de Piedade Coutinho en la construcción de la historia de las mujeres en deporte femenino en Brasil en el seculo XX. Efectuamos un análisis documental de las fuentes históricas en el período entre las décadas de 1930-1950, utilizando como punto de referencia la historia de las mujeres e la categoría de género. Concluimos que Piedade Coutinho fue una pionera en la inserción de las mujeres brasileñas en el deporte de competición, tiendo se destacado en los Juegos Olímpicos de 1936, 1948 y 1952, contribuyendo para transformarlas representaciones de género asociadas a las mujeres en la sociedad brasileña.

Palabras clave: Historia de las mujeres. Deportes. Natación. Género.

\section{Referências}

BRANDÃO, H. H. N. Introdução à Análise do Discurso. 3. ed. Campinas, SP: Editora da Unicamp, 2018. 
BURKE, P. (Org.). A escrita da História: novas perspectivas. 2. ed. São Paulo: Editora da Unesp, 2011.

CARDOSO, M. Os arquivos das Olimpíadas. São Paulo: Panda Books, 2000.

COB. Relatório dos Jogos Olímpicos de Londres. Rio de Janeiro: COB, 1948.

Relatório dos Jogos Olímpicos de Helsinque. Rio de Janeiro: COB, 1952.

COMITÉ ORGANIZADOR DE LOS SEGUNDOS JUEGOS DEPORTIVOS PANAMERICANOS. Memoria de los Segundos Juegos Deportivos Panamericanos. Mexico, 1955.

DEVIDE, F. P. A natação como elemento da cultura física feminina no início do século XX: construindo corpos saudáveis, belos e graciosos. Movimento. Porto Alegre, v. 11, n. 2, p. 125-144, 2004.

Atletas de Referência de Natação Feminina. In: COSTA, L. P. da. (Org.). Atlas do Esporte no Brasil. Rio de Janeiro: Shape, 2005b. p. 338.

Gênero e mulheres no esporte: história das mulheres nos jogos olímpicos modernos. Ijuí, RS: Ed. Unijuí, 2005a.

História das mulheres na natação brasileira no século $\mathrm{XX}$ : das adequações às resistências sociais. 2003. 347 f. Tese (Doutorado em Educação Física) - Programa de PósGraduação em Educação Física, Universidade Gama Filho, Rio de Janeiro, 2003.

História das mulheres na natação brasileira no século XX: das adequações às resistências sociais. São Paulo: Hucitec, 2012.

. Natação Feminina. In: COSTA, L. P. da. (Org.). Atlas do Esporte no Brasil. Rio de Janeiro: Shape, 2005c. p. 236-237.

Reflexões sobre o uso da linguagem e da imagem na pesquisa histórica do esporte: a trajetória de Blanche Pironnet na História das Mulheres no esporte no Brasil. Movimento. Porto Alegre, v. 23, n. 2, p. 675-688, 2017.

DEVIDE, F. P.; VOTRE, S. J. Doping e mulheres no esporte. RBCE. Campinas, v. 27, n. 1, p. 123-138, 2005.

. Primórdios da natação competitiva feminina: do 'páreo elegância' aos Jogos Olímpicos de Los Angeles. RBCE. Campinas, v. 34, p. 217-233, 2012.

DEVIDE, F. P. et al. Estudos de gênero na Educação Física Brasileira. Motriz. Rio Claro, v. 17, n. 1, p. 93-103, 2011.

ESPORTE ILUSTRADO. Rio de Janeiro, n. 422, p. 9, 9 maio 1946.

FLUMINENSE FOOTBALL CLUB. Rio de Janeiro, ano IX, n. 104, p. 5, 1 jan. 1949. 
GOELLNER, S. V. As atividades corporais e esportivas e a visibilidade das mulheres na sociedade brasileira do início deste século. Movimento. Porto Alegre, ano V, n. 9, p. 47-57, 1998.

Bela, maternal e feminina: imagens da mulher na Revista Educação Physica. Ijuí, RS: Unijuí, 2003.

. Feminismos, mulheres e esportes: questões epistemológicas sobre o fazer historiográfico. Movimento. Porto Alegre, v. 13, n. 2, p. 171-196, 2007.

JORNAL DOS SPORTS. Rio de Janeiro, ano VI, n. 2052, p. 6, 7 jul. 1936.

. Rio de Janeiro, ano VI, n. 2053, p. 1-4, 8 jul. 1936.

Rio de Janeiro, ano VI, n. 2086, p. 1-6, 15 ago. 1936.

. Rio de Janeiro, n. 5794, p. 1-6, 13 jul. 1948.

. Rio de Janeiro, n. 5801, p. 1-4, 21 jul. 1948.

Rio de Janeiro, n. 5815, p. 1, 6 ago. 1948.

Rio de Janeiro, n. 6924, p.1-6, 25 mar. 1952.

LOURO, G. L. Gênero, Sexualidade e Educação: uma perspectiva pós-estruturalista. 16. ed. Petrópolis, RJ: Vozes, 2017.

MOURÃO, L. Representação social da mulher brasileira nas atividades físico-desportivas: da segregação à democratização. Movimento. Porto Alegre, v. 6, n. 13, p. 5-18, 2000.

ORGANISATIONSKOMITEE FÜR DIE XI OLYMPIADE. XI Olympiade Berlin 1936 Amtlicher Bericht. Band II. Berlin, 1936. p. 940-976.

ORGANISING COMMITTEE FOR THE GAMES OF THE XV OLYMPIAD. The oficial report of the organizing committee for the XV Olympiad. Helsinque: COI, 1952. p. 585593.

ORGANISING COMMITTEE FOR THE XIV OLYMPIAD. The official report of the organising committee for the XIV Olympiad. London, 1948. p. 460-464.

PAIOLI, C. C. Brasil olímpico. São Paulo: Imprensa Oficial do Estado/IMESP, s.d.

PARRA, L. C. (Ed.). El libro de oro de la natación sudamericana 1929-1979. Equador: Federation Ecuatoriana de Natación, s.d.

PÊCHEUX, M. Semântica e discurso: uma crítica à afirmação do óbvio. 5. ed. Campinas, SP: Editora Unicamp, 2016.

PFISTER, G. A. A história delas no esporte: rumo a uma perspectiva feminista? In: ROMERO, E. (Org.). Mulheres em movimento. Vitória: Edufes, 1997. 
REVISTA DE EDUCAÇÃO FÍSICA. Rio de Janeiro, ano 4, n. 22, p. 14, maio 1935.

SCHPUN, M. R. Beleza em jogo: cultura física e comportamento em São Paulo nos anos 20. São Paulo: Boitempo, 1999.

SCOTT, J. Gênero: uma categoria útil de análise histórica. Educação \& Realidade. Porto Alegre, v. 20, n. 2, p. 71-99, 1995.

História das Mulheres. In: BURKE, Peter (Org.). A escrita da história: novas perspectivas. São Paulo: Editora Unesp, 2011. p. 62-95.

SHARPE, J. A História Vista de Baixo. In: BURKE, Peter (Org.). A Escrita da História: novas perspectivas. São Paulo: Editora UNESP, 2011.

SOIHET, R. História das Mulheres. In: CARDOSO, G. F.; VAINFAS, R. (Org.). Domínios da história. Rio de Janeiro: Campus, 2011. p. 275-296.

SPORT ILLUSTRADO. Rio de Janeiro, ano 3, n. 145, p. 3-8, 16 jan. 1941.

Rio de Janeiro, ano 3, n. 153, p. 3, 15-18, 13 mar. 1941.

UNITED STATES OLYMPIC COMMITTEE. Pan Am Games Record Guide - XIIIth Pan American Games. Canadá: U.S.O.C., 1999.

WENETZ, I.; SWENGBER, M. S. V.; DORNELLES, P. Caminhos teóricos e políticos no trato com a sexualidade na Educação Física: uma análise inicial das produções na área (20012015). In.: DORNELlES, P. G.; WENETZ, I.; SWENGBER, M. S. V. (Org.). Educação Física e sexualidade: desafios educacionais 1. Ujuí, RS: Unijuí, 2017. p. 23-49.

Recebido em: 17/03/2017

Revisado em: 11/04/2018

Aprovado em: 16/04/2018

Endereço para correspondência:

fabianodevide@uol.com.br

Fabiano Pries Devide

Universidade Federal Fluminense

Rua Miguel de Frias, 9

Icaraí

Niterói - RJ

24220-900 